\title{
OCCUPATIONAL EXPOSURE TO TRICHLOROETHYLENE AND CANCER RISK FOR WORKERS AT THE PADUCAH GASEOUS DIFFUSION PLANT
}

\author{
DEBRA E. BAHR ${ }^{1}$, TIMOTHY E. ALDRICH ${ }^{1,2}$, DAZAR SEIDU ${ }^{1}$, GAIL M. BRION ${ }^{1}$, DAVID J. TOLLERUD ${ }^{3}$, \\ and THE PADUCAH GASEOUS DIFFUSION PLANT PROJECT TEAM (SUSAN MULDOON, NANCY REINHART, \\ AHMED YOUSEEFAGHA, PAUL MCKINNEY, THERESE HUGHES, CAROLINE CHAN) ${ }^{4}$; (CAROL RICE, \\ DAVID E. BREWER, RONALD W. FREYBERG, ADRIANE MOSER MOHLENKAMP, KRISTEN HAHN, \\ RICHARD HORNUNG, MONA HO); (ANIRUDDHA DASTIDAR, SAMANTHA FREITAS, DANIEL SAMAN, \\ HEGE RAVDAL, DOUGLAS SCUTCHFIELD) ${ }^{6}$; (CONTRACTORS: KENNETH J. EGER, STEVE MINOR)
}

${ }^{1}$ University of Kentucky, College of Public Health, Lexington, KY, USA

${ }^{2}$ East Tennessee State University, Johnson City, TN, USA

Department of Public Health

${ }^{3}$ University of Louisville, School of Public Health and Information Sciences, Louisville, KY, USA

Department of Environmental \& Occupational Health Sciences

${ }^{4}$ University of Louisville, Louisville, KY, USA

${ }^{5}$ University of Cincinnati, Cincinnati, OH, USA

${ }^{6}$ University of Kentucky, Lexington, KY, USA

\begin{abstract}
Objective: The Paducah Gaseous Diffusion Plant (PGDP) became operational in 1952; it is located in the western part of Kentucky. We conducted a mortality study for adverse health effects that workers may have suffered while working at the plant, including exposures to chemicals. Materials and Methods: We studied a cohort of 6820 workers at the PGDP for the period 1953 to 2003; there were a total of 1672 deaths to cohort members. Trichloroethylene (TCE) is a specific concern for this workforce; exposure to TCE occurred primarily in departments that clean the process equipment. The Life Table Analysis System (LTAS) program developed by NIOSH was used to calculate the standardized mortality ratios for the worker cohort and standardized rate ratio relative to exposure to TCE (the U.S. population is the referent for ageadjustment). LTAS calculated a significantly low overall SMR for these workers of 0.76 (95\% CI: 0.72-0.79). A further review of three major cancers of interest to Kentucky produced significantly low SMR for trachea, bronchus, lung cancer (0.75, 95\% CI: 0.72-0.79) and high SMR for Non-Hodgkin's lymphoma (NHL) (1.49, 95\% CI: 1.02-2.10). Results: No significant SMR was observed for leukemia and no significant SRRs were observed for any disease. Both the leukemia and lung cancer results were examined and determined to reflect regional mortality patterns. However, the Non-Hodgkin's Lymphoma finding suggests a curious amplification when living cases are included with the mortality experience. Conclusions: Further examination is recommended of this recurrent finding from all three U.S. Gaseous Diffusion plants.
\end{abstract}

Key words:

Cohort study, Gaseous diffusion plant, Trichloroethylene, Healthy worker effect

Received: July 29, 2010. Accepted: December 1, 2010.

This work is funded by the Health Effects of Occupational Exposures in PGDP (Paducah Gaseous Diffusion Plant) workers - a study of the National Institute for Occupational Safety and Health (NIOSH): R01-OH-007650.

Address reprint request to T.E. Aldrich, University of Kentucky, College of Public Health, 121 Washington Avenue, Lexington, KY 40536-003, USA (e-mail: ALDRICH@mail.etsu.edu). 


\section{INTRODUCTION}

The Paducah Gaseous Diffusion Plant (PGDP) is a uranium enrichment plant that became operational in September, 1952. The PGDP is located approximately 10 miles west of the city of Paducah in the western part of Kentucky. The plant still functions to enrich uranium through a series of cascades designed to remove impurities from the product of choice. The process of gaseous diffusion allows for Uranium Fluoride (UF $)$ to diffuse through a cascade in which Uranium ${ }^{235}$ is removed from the combined Uranium $^{235}$ and Uranium ${ }^{238}$ gases. This product is then used in commercial reactors or transferred to other plants for further refinement [1].

Concerns have been raised about the adverse health effects that workers may have suffered while or after performing specific tasks at the plant. Community concerns about the health outcomes among the PGDP workers led to the development of the PGDP study. Based on recommendations from the National Institute for Occupational Health and Safety (NIOSH), the PGDP study was designed to be completed in three phases. The first stage involved a feasibility study completed in January 2003. The second stage was a pilot study completed in January of 2004. The third stage was an evaluation of worker mortality related to workplace exposures [1]. This paper provides results from the third stage, with special emphasis on worker exposure to trichloroethylene.

\section{BACKGROUND}

Trichloroethylene (TCE) is a nonflammable, colorless liquid at room temperature with a sweet odor and a sweet, burning taste. TCE is taken up by direct contact through the skin, ingestion, and by inhalation. When TCE enters the human body, it may break down into dichloroacetic acid, trichloroacetic acid, chloral hydrate, or 2-chloroacetaldehyde; all of which are toxic to animals and humans [2].
It undergoes metabolic activation primarily in the liver, but also in the kidneys and lungs [3].

A major concern of occupational exposure to TCE is that it may cause cancer. Studies have classified TCE as a probable human carcinogen. Long-term occupational exposure to TCE may result in Non-Hodgkin's lymphoma, renal cell carcinoma, cervical cancer, multiple myeloma, kidney cancer, and cancer of the liver and biliary tract [3-5].

Based on conversations with current and former workers, Moser established that workers at the PGDP were exposed to TCE primarily in departments that clean the process equipment as TCE was used to degrease fabricated metal parts [6]. The job titles with the highest TCE exposures were: laboratory, maintenance/electrician, maintenance/ lubrication, waste operations, and chemical operator.

Past research of human exposures reveals that very few studies have isolated TCE exposure from other chemical exposures [2]. To determine if there was any relationship between exposures experienced while working at the PGDP and premature mortality, standardized mortality ratios (SMR) and standardized rate ratios (SRR) were calculated. A SMR is defined as the ratio of the observed deaths compared to (divided by) the deaths that would have been expected in the cohort had they experienced the same death rates as the reference population; person-years at risk are used to weight the expected rates. A SRR is the ratio of two standardized rates within the same cohort - the exposed portion of the cohort's age standardized rate compared to (divided by) the unexposed portion of the cohort's age standardized rate using the person-years at risk to weight the rates.

\section{METHODS}

A Job Exposure Matrix was developed by Moser based on discussions with current and past employees at the plant [6]. Each job title was ranked by classifying the likelihood of short-term exposure to TCE from zero, being no 
possibility of exposure, through 5 , being most probable of exposure. These exposure levels are qualitative only, and as such, have no mathematical relationship - an exposure of 4 is not twice the exposure of 2 .

The Life Table Analysis System (LTAS) program developed by NIOSH was used to calculate the SMR for the worker cohort and SRR relative to exposure to TCE [7]. LTAS requires three distinct files to conduct the analyses - person, work history, and outcome files. The person file consisted of a numerical identifier for each worker, sex, race, date of birth, hire date, and date last observed which could be date of death, date last observed or end of study date. The work history file contained the identifier for each worker, a separate line for each job title held by the worker, the start and end date for the job, and the TCE exposure ranking of each job. The outcome file provided the identifier and date of death and cause of death using the International Classification of Diseases (ICD) code in use at the time of death. A nosologist provided the ICD code in use at the time of death for those death certificates for which an ICD code was not provided. These files provided an overall SMR for the workers and provided SMRs for specific disease states with additional separation of the workers by race and gender. LTAS used the current ICD code at time of death.

In order to make SMR comparisons of workers exposed to different TCE exposure levels, it was necessary to determine which exposure levels were most alike or different. The project industrial hygienist stated that TCE exposure levels zero and 1 were similar and TCE exposures 4 and 5 were similar. She was uncertain as to which group TCE exposure levels 2 and 3 should be combined [8]. The following worker TCE exposure level groups were developed: zero exposure, zero or 1 exposure, 2 or 3 exposure, 4 or 5 exposure, and a group of workers with an exposure of zero to 3 as a comparison group to workers with an exposure of 4 or 5 (Table 1).

In order to use LTAS to calculate TCE SMRs and SRRs, new files were created. For the SMR calculation
Table 1. Formation of trichloroethylene (TCE) exposure groups

\begin{tabular}{ll}
\hline \multicolumn{1}{c}{ TCE exposure level $0^{\mathrm{a}}$} & TCE exposure group $0^{\mathrm{b}}$ \\
\hline TCE exposure level 0 & TCE exposure group 1 \\
TCE exposure level 1 & TCE exposure group 2 \\
TCE exposure level 2 & \\
TCE exposure level 3 & TCE exposure group 3 \\
TCE exposure level 0 & \\
TCE exposure level 1 & \\
TCE exposure level 2 & \\
TCE exposure level 3 & TCE exposure group 4 \\
TCE exposure level 4 & \\
TCE exposure level 5 & \\
\hline & \\
& \\
&
\end{tabular}

person, work history and outcome files were created for each TCE exposure group. The first step was to reduce the history file, for each exposure group, such that each worker only had one work history line versus the multiple lines for each respective job title in the original history file. The begin date was based on the date first exposed to TCE. For all exposure groups the end date was the date of death or end of study. The person file was changed such that the date last observed was the date of death or end of study. No changes were made to the outcome file. Changes to the work history file were made such that each worker was assigned the number zero to 3 based on the category number as defined above. For exposure categories zero, 1 , and 2 the begin date would be the date of hire. For category 3 the begin date was the date at which the worker first experienced a TCE exposure of 4 or 5 . Analyses were done by exposure level or group of exposure levels.

For calculating the SRR only one set of person, work history, and outcome files were required. In order to calculate the SRR, the TCE exposure groups used to calculate the TCE exposure SMR had to be combined into four TCE categories such that each worker would only be in one category (Table 2). 
Table 2. Formation of trichloroethylene (TCE) categories

\begin{tabular}{ll}
\hline \multicolumn{1}{c}{ TCE exposure level $0^{\mathrm{a}}$} & TCE category $0^{\mathrm{b}}$ \\
\hline TCE exposure level 1 & TCE category 1 \\
TCE exposure level 2 & TCE category 2 \\
TCE exposure level 3 & \\
TCE exposure level 4 & TCE category 3 \\
TCE exposure level 5 & \\
\hline
\end{tabular}

${ }^{a}$ Moser exposure levels

${ }^{\mathrm{b}}$ Categories used to calculate SRRs.

Owing to a finding related to lung cancer and leukemia risk, an adjustment for regional effects was made. Respective, age-adjusted, race- and gender-specific lung cancer mortality rates were obtained from the National Center for Health Statistics [9]. Smoking prevalence rates were based upon self-reported prevalence of smoking by the national Behavioral Risk Factor Surveillance System back to 1985 [10]. Before 1985, smoking prevalence rate estimates were extrapolated from the series of Surgeon General Reports back to 1964 [11]. The race, gender-specific cigarette smoking prevalence values were extrapolated back to 1953, applying Bayesian scaling from the respective year-specific lung cancer mortality rates [12]. These lung cancer mortality estimates assume a constant risk relationship between cigarette smoking and lung cancer mortality risk. The focus for these analyses was for only Caucasian males as they represented the largest fraction of the PGDP cohort, and comprised $76 \%$ of the lung cancer deaths. Risk of a simple ecologic fallacy is patent with a localized workforce.

Next, owing to the findings related to non-Hodgkin's Lymphoma, we endeavored to account for the cancer risk in the cohort incorporating cancer cases who did not die from their disease. Mortality data alone incorporates a bias for survivability of the specific disease. In recent years the survivorship for NHL has improved dramatically. The person-years for the PGDP cohort were determined, in 5-year age increments, for 1995-2004. The Prevalence section of the National Cancer Institute's Statistical Report was used to derive approximate expected numbers of cases, for the 10-year period [13]. These expected numbers were compared to the observed case counts, by site, as identified by the Kentucky Cancer Registry (KCR). This assessment was intended to be entirely descriptive in nature, so no hypothesis tests were performed.

\section{RESULTS}

The final worker file contained a total of 6820 workers of which 6766 workers had usable data. Of these 6766 workers, 5128 were alive and 1638 had died. Male workers were selected for the TCE exposure analysis; 5535 total. These were comprised of 4972 white males, and 563 males of other races. See Table 3. The rationale for excluding the females was simply too few female deaths occurred among female workers in any TCE exposure category other than 0 .

The overall SMR for the PGDP workers with useable job exposure was 0.76 . The overall SMR for the group of PGDP workers with a zero TCE exposure was 0.78 ; the SMR for the group of workers with zero or 1 TCE exposure was 0.73 ; the SMR for the group of workers with 2 or 3 TCE exposure was 0.76 ; the SMR for the group of workers with 0-3 TCE exposure was 0.75; and the SMR for the group of workers with ever a 4 or 5 TCE exposure was 0.71 . All SMRs showed reduced mortality relative to the nation; all were significant except for the zero exposure group (Table 4). The maleonly SMR data were virtually the same as the full cohort, e.g., all SMRs less than the U.S. expected rates and no evidence of a gradient of risk of death from any cause appeared with gradient of TCE exposure. From this point forward, in the site-specific analyses, only data for male exposure to TCE were examined.

Residents of the Commonwealth of Kentucky have voiced particular interest about PGDP for three cancer sites based upon their regional distribution (trachea, bronchus, 
Table 3. Paducah Gaseous Diffusion Plant Cohort Description (1952-2003)

\begin{tabular}{lcrrccc}
\hline \multirow{2}{*}{$\begin{array}{l}\text { Race and Gender } \\
\text { Group }\end{array}$} & $\mathrm{N}$ & \multicolumn{3}{c}{ Total } & \multicolumn{3}{c}{ Used with TCE Exposure Study } \\
\cline { 3 - 7 } & $(\%)$ & alive & deaths & $\begin{array}{c}\text { alive at end of } \\
\text { Cohort Period }\end{array}$ & $\begin{array}{c}\text { died during } \\
\text { Cohort Period }\end{array}$ & Total \\
\hline White males & $5016(74)$ & 3744 & 1272 & 3711 & 1261 & 4972 \\
White females & $1069(16)$ & 1001 & 68 & & not used & \\
Other races male & $564(8)$ & 251 & 312 & 251 & 312 & 563 \\
$\begin{array}{l}\text { Other races } \\
\quad \text { female }\end{array}$ & $171(2)$ & 151 & 20 & & not used & \\
Total & $6820^{*}$ & 5147 & 1672 & 3962 & 1573 & 5535 \\
\hline
\end{tabular}

TCE - trichloroethylene.

* Includes persons not included with the TCE exposure study.

Women were not used because too few deaths were in any other Exposure Category except 0 .

Table 4. SMRs for male Paducah Gaseous Diffusion Plant cohort members*, by TCE exposure level

\begin{tabular}{ccccc}
\hline & & & Male & \\
& Total cohort & white & other & total \\
\cline { 3 - 5 } & & $0.77^{* *}$ & $0.60^{* *}$ & $0.76^{* *}$ \\
Overall SMR & $0.76^{* *}$ & $(0.73-0.81)$ & $(0.49-0.72)$ & $(0.72-0.79)$ \\
95\% CI & $(0.72-0.79)^{* * *}$ & $\mathrm{n}=136$ & $\mathrm{n}=1340$ \\
Deaths & $\mathrm{n}=1638$ & $\mathrm{n}=1204$ & 2.41 & 0.72 \\
TCE Exposure & 0.78 & 0.71 & $(0.06-13.44)$ & $(0.49-1.04)$ \\
of 0 & $(0.57-1.04)$ & $(0.47-1.02)$ & $\mathrm{n}=1$ & $\mathrm{n}=28$ \\
Deaths & $\mathrm{n}=46$ & $\mathrm{n}=27$ & 0.81 & $0.74^{* *}$ \\
TCE Exposure & $0.73^{* *}$ & $0.74^{* *}$ & $(0.40-1.44)$ & $(0.65-0.85)$ \\
of 0 or 1 & $(0.65-0.81)$ & $(0.64-0.85)$ & $\mathrm{n}=14$ & $\mathrm{n}=190$ \\
Deaths & $\mathrm{n}=327$ & $\mathrm{n}=176$ & $0.70^{* *}$ & $0.76^{* *}$ \\
TCE Exposure & $0.76^{* *}$ & $0.77^{* *}$ & $(0.55-0.88)$ & $(0.70-0.83)$ \\
of 2 or 3 & $(0.70-0.82)$ & $(0.72-0.84)$ & $\mathrm{n}=76$ & $\mathrm{n}=518$ \\
Deaths & $\mathrm{n}=584$ & $\mathrm{n}=442$ & $0.71^{* *}$ & $0.76^{* *}$ \\
TCE Exposure & $0.75^{* *}$ & $0.76^{* *}$ & $(0.57-0.88)$ & $(0.70-0.81)$ \\
of 0,1,2,or 3 & $(0.70-0.80)$ & $(0.71-0.82)$ & $\mathrm{n}=90$ & $\mathrm{n}=708$ \\
Deaths & $\mathrm{n}=911$ & $\mathrm{n}=618$ & $0.38^{* *}$ & $0.71^{* *}$ \\
TCE Exposure & $0.71^{* *}$ & $0.74^{* *}$ & $(0.25-0.56)$ & $(0.66-0.77)$ \\
of 4 or 5 & $(0.66-0.76)$ & $\mathrm{n}=.68-0.79)$ & $\mathrm{n}=46$ & $\mathrm{n}=632$ \\
Deaths & $\mathrm{n}=727$ & $\mathrm{n}=586$ & \\
\hline
\end{tabular}

SMR — standardized mortality ratios, TCE — trichloroethylene.

* Workers with complete exposure information as needed per LTAS requirements.

** Two-Sided $\mathrm{P}<0.01$.

$* * * 95 \%$ Confidence Interval.

and lung cancer; Non-Hodgkin's lymphoma; and leukemia). A significantly lower SMR was found in the TCE exposure group 4 or 5 for trachea, bronchus and lung cancer (0.63); in the overall cohort this site-specific SMR was 0.75 . A significantly high SMR was found for TCE exposure group of 0-3 for Non-Hodgkin's lymphoma (1.76); 
Table 5. Disease-specific SMRs for male Paducah Gaseous Diffusion Plant cohort members, by TCE exposure level

\begin{tabular}{lcccccc}
\hline \multirow{2}{*}{ Causes of deaths } & Overall & \multicolumn{5}{c}{ TCE exposure } \\
\cline { 3 - 6 } & & group 0 & group 0-1 & group 2-3 & group 0-3 & group 4-5 \\
\hline Trachea, Bronchus & $0.75^{* *}$ & 1.03 & 0.76 & 0.86 & 0.82 & $0.63^{* *}$ \\
and Lung & $(0.72-0.79)^{* * *}$ & $(0.34-2.41)$ & $(0.51-1.09)$ & $(0.64-1.12)$ & $(0.65-1.02)$ & $(0.48-0.80)$ \\
Deaths & $\mathrm{n}=146$ & $\mathrm{n}=5$ & $\mathrm{n}=29$ & $\mathrm{n}=54$ & $\mathrm{n}=83$ & $\mathrm{n}=63$ \\
Non-Hodgkin's & $1.49^{*}$ & 3.20 & 1.85 & 1.70 & $1.76^{*}$ & 1.05 \\
Lymphoma & $(1.02-2.10)$ & $(0.39-11.57)$ & $(0.85-3.52)$ & $(0.88-2.97)$ & $(1.09-2.69)$ & $(0.52-1.88)$ \\
Deaths & $\mathrm{n}=32$ & $\mathrm{n}=2$ & $\mathrm{n}=9$ & $\mathrm{n}=12$ & $\mathrm{n}=21$ & $\mathrm{n}=11$ \\
Leukemia and & 1.15 & 0.00 & 0.90 & 0.72 & 0.79 & 1.47 \\
Aleukemia & $(0.74-1.72)$ & $(0.00-9.12)$ & $(0.24-2.30)$ & $(0.23-1.69)$ & $(0.36-1.50)$ & $(0.82-2.43)$ \\
Deaths & $\mathrm{n}=24$ & $\mathrm{n}=0$ & $\mathrm{n}=4$ & $\mathrm{n}=5$ & $\mathrm{n}=9$ & $\mathrm{n}=15$ \\
\hline
\end{tabular}

SMR — standardized mortality ratios, TCE — trichloroethylene.

* Two-Sided $\mathrm{P}<0.05$.

** Two-Sided $\mathrm{P}<0.01$.

$* * * 95 \%$ Confidence Interval.

while the entire cohort's SMR was 1.49. No significant SMR was found for leukemia in the overall cohort or for any TCE exposure level (Table 5).

As a secondary calculation, LTAS was used to calculate SRRs. The reference category for the overall calculation was the TCE zero exposure category. The overall SRR was 1.08 (95\% CI: 0.79-1.48). Due to zero or low numbers of deaths within the non-white cohort, only SRRs from the white cohort will be reported. As with the SMR calculations, SRRs were calculated for trachea, bronchus, and lung cancer, Non-Hodgkin's lymphoma, and leukemia.
The SRR for trachea, bronchus and lung was 0.72 . Due to the lack of deaths from the specified causes in the TCE zero exposure category, TCE exposure category 1 became the reference group for Non-Hodgkin's lymphoma and leukemia: the SRR for Non-Hodgkin's lymphoma was 0.99 and the SRR for leukemia was 1.40. See Table 6. While it was noted that no SRRs were significant, a trend was observed in which workers in TCE exposure category 2 (exposure groups 2 and 3) did have a higher SRR in all disease states except leukemia, than workers in TCE exposure categories 0,1 or 3 .

Table 6. Disease-specific SRRs for male Paducah Gaseous Diffusion Plant cohort members, by TCE exposure level

\begin{tabular}{|c|c|c|c|c|c|}
\hline \multirow{2}{*}{ SRR } & \multicolumn{4}{|c|}{ TCE category } & \multirow{2}{*}{ Total } \\
\hline & 0 & 1 & 2 & 3 & \\
\hline All causes & 1.00 & $0.88(0.63-1.23)^{*}$ & $1.19(0.86-1.64)$ & $1.14(0.83-1.56)$ & $1.08(0.79-1.48)$ \\
\hline Trachea, bronchus and lung & 1.00 & $0.58(0.22-1.54)$ & $0.97(0.39-2.46)$ & $0.67(0.27-1.69)$ & $0.72(0.29-1.76)$ \\
\hline Non-Hodgkin’s lymphoma & - & 1.00 & $1.31(0.47-3.65)$ & $0.75(0.27-2.12)$ & $0.99(0.40-2.46)$ \\
\hline Leukemia & - & 1.00 & $0.73(0.15-3.45)$ & $1.89(0.61-5.86)$ & $1.40(0.46-4.24)$ \\
\hline Biliary passages and liver & - & 1.00 & $0.34(0.05-2.07)$ & $0.39(0.08-1.94)$ & $0.43(0.10-1.84)$ \\
\hline Kidney & NR & NR & NR & NR & NR \\
\hline
\end{tabular}

SRR — standardized rate ratios, TCE — trichloroethylene, NR — none to report.

* $95 \%$ Confidence Interval. 


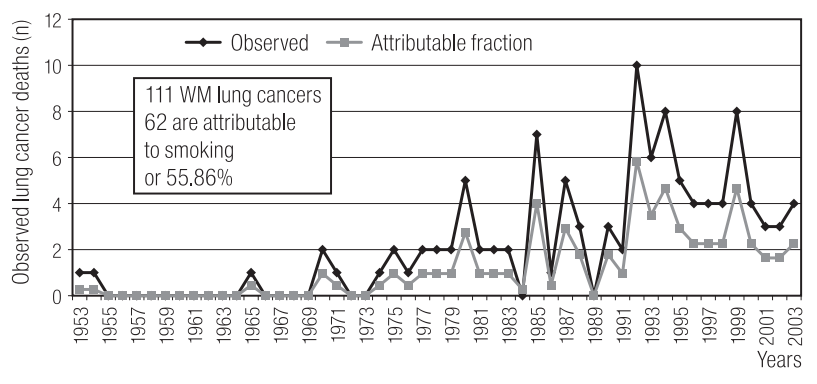

These estimates assume a constant risk relationship between cigarette smoking and lung cancer mortality risk.

Fig. 1. Observed lung cancer deaths among white males $(\mathrm{n}=111)$ in the Paducah Gaseous Diffusion Plant cohort 1953-2003 (ordinate), compared by year (abscissa) to the fraction of lung cancer deaths that would have been 'expected' based on the (geographic) regional population's cigarette smoking prevalence rates.

For the observed lung cancer deaths among Caucasian males ( $n=111$ ), $55.86 \%$ were found to be attributable to cigarette smoking risk by applying the estimated regional population prevalence (Figure 1). During the period when the PGDP numbers of lung cancer deaths rose sharply (1985-2000), the attributable fraction also rose, suggesting that the cohort's rising lung cancer mortality was more influenced by cigarette smoking prevalence, than by potential occupational risks. These death counts were translated into age-adjusted, race-, gender-specific annual rates. See Figure 2. The rise and decline of the lung cancer mortality patterns within the PGDP cohort are virtually the same as the U.S. and often below the Kentucky rates.

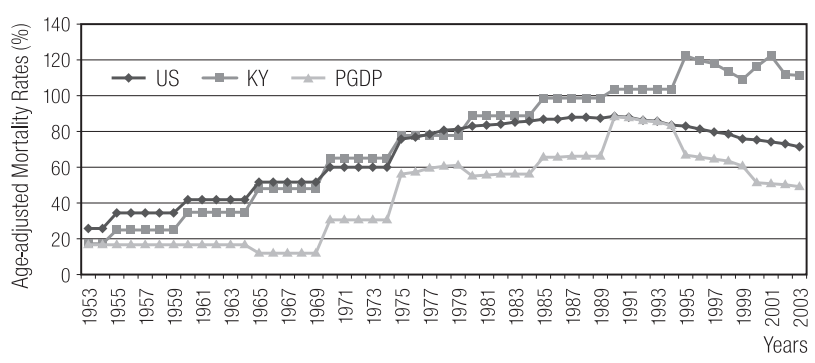

Fig. 2. U.S., Kentucky, and Paducah Gaseous Diffusion Plant (PGDP) Age-adjusted Mortality Rates, by year, for Caucasian Males 1953-2003.
A regional analysis of leukemia mortality for the state of Kentucky indicated that the mortality rates around PGDP were higher than for the balance of the state [13]. As with lung cancer, the regional leukemia rates reflected more of a U.S. mortality pattern. However, the good survival associated with many types of leukemia led to a question of the impact for including cancer cases that did not die of their diagnosis.

There were 202 cancer deaths from the PDGP cohort that occurred in Kentucky (over 50 years). By contrast, there were 431 prevalent cases found among the PGDP cohort in Kentucky (over 10 years). These 431 cancer cases identified by KCR compares to 436.5 cancer cases expected based on the person years distribution; this represents $98.85 \%$ case ascertainment. There were 176.5 expected cancer deaths for this cohort age, race, gender distribution, in the ten year period. This makes the simple SMR for the Kentucky fraction of the PGDP cohort experience 1.14. Figure 3 shows the progression by age of the person years in the Kentucky fraction of the PGDP cohort, with the corresponding expected cancer cases.

The lesser case counts in the early ages are a familiar age-specific pattern for cancer incidence. As age increases, so too does the expectation of cancer cases into the high cancer incidence ages (50-80 years). The peculiar dip of expected cases may signal a rebound that has been

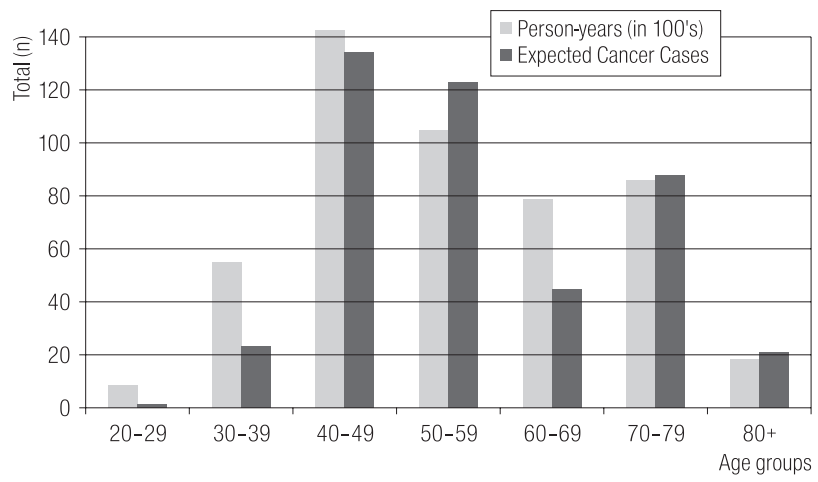

Fig. 3. Person-years in 100's and the Expected Cancer Case Counts for the KY portion of the Paducah Gaseous Diffusion Plant study. 


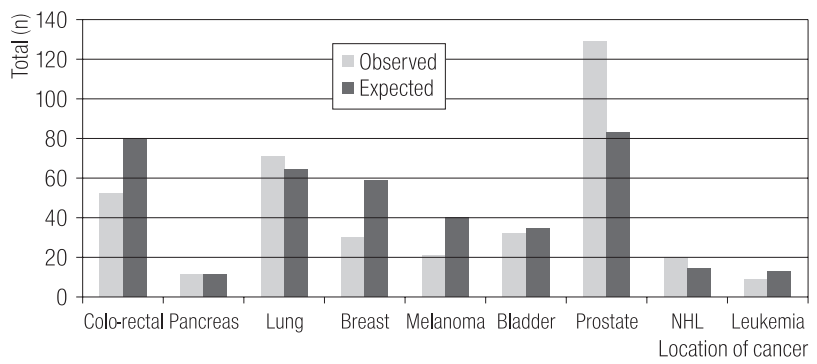

Fig. 4. Observed Prevalent Cancer cases in the KY fraction of the Paducah Gaseous Diffusion Plant Cohort (1995-2004), and the corresponding Expected Prevalent Cases [13].

postulated for the Healthy Worker Effect (HWE) [14,15]. Person reaching retirement age are healthier than the general population. The PGDP workers were under splendid medical surveillance in this decade. Note the excess case expectation for the 50-59 age-group. This may suggest earlier case-finding for some cancers, thus a lowering of mortality, and a lower case rate at retirement age.

Figure 4 shows the site-specific distribution of the $431 \mathrm{KY}$ cancer prevalence cases. The observed cases for colo-rectal cancer, breast cancer and melanoma reflect the described lesser incidence among a 'healthy worker' population $[14,15]$. $\mathrm{Cu}$ riously, the two 'elevated' cancer sites also reflect improved case survival for early diagnosed cancer with a poor mortality rate (lung cancer) and one with splendid screening potential (prostate cancer).

Figure 5 enhances these perspectives of the relative number of cancer deaths versus living prevalent cases. The implication of these conflicting selective HWE-impacted

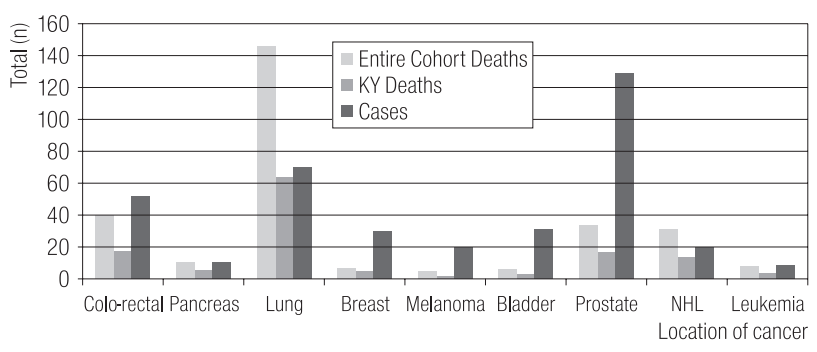

Fig. 5. Cancer deaths in Entire Paducah Gaseous Diffusion Plant (PGDP) Cohort (1952-2004) vs. PGDP Cohort Deaths in Kentucky (1995-2004), and Prevalent Cases in Kentucky (1995-2004). survival relationships may be speculated upon for the Non-Hodgkin's Lymphoma (NHL) pattern in this cohort, supporting a possible TCE exposure relationship [15].

\section{DISCUSSION}

William Ogel, in 1885, is reported to have noted two issues when calculating death in industrial workers - "considerable standard of muscular strength" and "vigour to be maintained": the healthy worker effect (HWE). Healthier workers will seek employment and because of their good health will continue to be employed [16]. Thirty percent of the workers at the PGDP worked more than 40 years at the plant. The overall SMR of 0.76 speaks to the overall health of the PGDP workers.

Due to TCE's complex mechanism of metabolism, observed effects and mode of action, there are many diverse views on the health risks of TCE [17]. Based on numerous reviews, TCE has only been shown to be "probably" or "reasonably anticipated to be" carcinogenic to humans [18]. The strongest links between TCE exposure and cancers is with liver cancer, kidney cancer, and lymphomas $[18,19]$. None of the PGDP exposure groups showed a significant SMR for liver or kidney cancer (see Table 6). The workers in the TCE exposure group 0-3 did show a significant SMR for Non-Hodgkin's lymphoma of 1.76. The workers who experienced the highest exposures to TCE (exposure group 4 or 5) worked in the laboratory, as maintenance/electricians, in maintenance/lubrication, in waste operations or as chemical operators [4]. Of these workers, those who were chemical operators, maintenance/electricians, and in maintenance/lubrication, were also exposed to elevated levels of arsenic, beryllium, hexavalent chromium, nickel, and uranium [20]. The multiple exposures create difficulty in assigning the cause of health effects to any single agent such as TCE.

One possible means of reducing the healthy worker effect is by making comparisons from within the cohort. 
Calculating the SRR provides this comparison. However, Arrighifound that even when using an internal reference group, the HWE still decreases the exposure effect [21]. Using TCE 0 or TCE 1 as the reference groups showed no significant relationships between TCE and the five cancers reviewed. Mandel performed a meta-analysis of occupational TCE exposure with special emphasis on Non-Hodgkin's lymphoma [22]. His analysis of standard relative risk estimates based on TCE exposure did not show an exposure response trend.

Table 6 shows the SRRs for the cohort and three diseases. Note that TCE exposure category 2 (exposure 2 or 3) has higher SRRs than the other exposure categories. The leukemia SRRs do not follow this trend, but rather has its apex SRR at TCE exposure category 3 (exposure of 4 and 5). Possibly, higher exposed workers were 'protected' from their recognized leukemia risk from TCE exposure, while lesser exposed workers may have been less well protected.

The concept of the healthy worker effect has been studied for over 100 years, but there is no agreed-upon method for controlling for this effect. However, it appears that the workers at the PGDP were not negatively affected by exposures based on the calculated SMRs. Based on these classic analyses, mortality due to chemical exposure is not apparent and overshadowed by the HWE. However, the HWE also poses a potential for superior medical surveillance compared to the general population. This may possibly lead to earlier disease detection and thus a potential for better survival. In the case of NHL, this selective worker benefit is implicated and poses reinforcement for a possible TCE exposure risk among moderately or less exposed workers.

One particular recurring finding for the epidemiologic studies of the three U.S. gaseous diffusion plants is that of moderately elevated Non-Hodgkin's Lymphoma (NHL) among the cohort members [23-25]. One effect of the HWE is that well-medically served employees at federal facilities are closely monitored, particularly for cancer risk, then cancer cases may be detected earlier and treated more successfully than in the general population. The lung cancer and prostate cancer patterns in Figures 4 and 5 offer illustrations of this HWE-related selection force (better medical surveillance) operating with cancers with respectively poor and excellent, screening detection potential and survival rates.

Occupational studies would ascribe these lower mortality patterns to the HWE and perhaps look no farther into the experience, particularly if the number of events is relatively few.

In Figure 5, all cancer site patterns for prevalence greatly outstrip the respective mortality patterns, generally reflecting the objective of this article that integration of the 'incidence fraction' of the force of morbidity with the mortality fraction produces more case outcomes to reason over. However, in Figure 4, one may see that NHL period prevalence surpasses its respective 'expected' prevalence, this is just as NHL did for its respective mortality experience (see Table 5) [23-25]. Consequently, the improved survivorship would act to lower the mortality risk (reducing the death count - lowering the SMR) to statistically marginal findings that may be dismissed as an artifact of the HWE. Then, when the NHL incidence also surpasses expectation, that segment of the selection force is effectively missed in occupational studies without populationbased cancer registry support. The resulting impact being that a biologically credible risk relationship for NHL is 'diminished' in informative perspective of an occupational cohort where the 'true' excess NHL deaths (had the workforce survival not been greater than the general public's) are hidden among the incidence fraction. We believe this potential selection force needs further study, especially among the three gaseous diffusion plant cohorts [15,16,21,23-25].

In Kentucky, the lung cancer mortality rates rose from the lowest quintile before 1970 to lead the nation by 1995 . This article describes the impact of divergent secular 
trends (national versus state) upon the lung cancer mortality experience of workers at the Paducah (KY) Gaseous Diffusion Plant. During the cohort follow-up, the national pattern for lung cancer mortality is observed rather than the Kentucky trend. Such adjustment for regional behavioral risk factor prevalence is important with epidemiologic research to avoid a simple ecologic fallacy when studying a localized population, as a single industrial facility.

\section{ACKNOWLEDGEMENTS}

Appreciation is expressed to the Kentucky Cancer Registry for its assistance with the analyses reported in this paper.

\section{REFERENCES}

1. Tollerud DJ. Health Effects of Occupational Exposures in PGDP Workers [grant application]. 2003 November 12.

2. Agency for Toxic Substances and Disease Registry. Toxicological Profile for Trichloroethylene (TCE). Atlanta; 1997 [cited 2009 Jul 14]. Available from URL: http://www.atsdr.cdc. gov/toxprofiles/tp.asp?id=173\&tid $=30$.

3. Pastino GM, Yap WY, Carroquino M. Human Variability and Susceptibility to Trichloroethylene. Environ Health Perspect 2000;108 (Suppl 2):201-14.

4. Moser A. Estimating Historical Trichloroethylene Exposure in Uranium Enrichment, Gaseous Diffusion Plant [master's thesis]. Cincinnati (OH): Univ. of Cincinnati; 2005.

5. Raaschou-Nielsen O, Hansen J, McLaughlin JK, Kolstad H, Christensen JM, Tarone RE, et al. Cancer Risk among workers at Danish companies using trichloroethylene: A Cohort Study. Am J Epidemiol 2003;158(12):1182-92.

6. Warrenberg D. Trichloroethylene and Cancer: Epidemiologic Evidence. Environ Health Perspect 2000;108 (Suppl 2): 161-76.

7. Life Table Analysis System. Version 2.0.16. NIOSH; 2008 [cited 2006 May 15]. Available from URL: http://www.cdc. gov/niosh/ltas.
8. Rice C. University of Cincinnati - member of the Paducah Gaseous Diffusion Plant team. Personal correspondence. April 25, 2008.

9. Rybicki BA, Johnson CC, Peterson EL, Kortsha GX, Gorell JM. Comparability of different methods of retrospective exposure assessment of metals in manufacturing industries. Am J Ind Med 1997;31(1):36-43.

10. Steenland K, Bray I, Greenland S, Boffetta P. Empirical Bayes adjustments for multiple results in hypothesis-generating or surveillance studies. Cancer Epidemiol Biomarkers Prev 2000;9(9):895-903.

11. Devesa SS, Grauman DJ, Blot WJ, Pennello G, Hoover RN, Fraumeni JF Jr. Atlas of cancer mortality in the United States, 1950-94. Washington, DC: US Govt Print Off; 1999. NIH Publ No. (NIH) 99-4564. [cited 2009 Jun 30]. Available from URL http://cancercontrolplanet.cancer.gov/atlas/ index.jsp.

12. Saad F, Ravdal H, Aldrich TE. Unstaged Lung Cancer in Kentucky: Good News. J Ky Med Assoc 2006;104(12):1-5.

13. National Cancer Institute. SEER Cancer Statistics Report: 1975-2006 [cited 2009 May 20]. Available from URL: http://seer.cancer.gov/csr/1975_2006/results_merged/topic_ prevcounts.pdf.

14. Baillargeon J, Wilkinson G, Rudkin L, Baillargeon G, Ray L. Characteristics of the healthy worker effect: a comparison of male and female occupational cohorts. J Occup Environ Med 1998;40(4):368-73.

15. Siebert U, Rothenbacher D, Daniel U, Brennera H. Demonstration of the healthy worker survivor effect in a cohort of workers in the construction industry. Occup Environ Med 2001;58(12):774-799.

16. Fox AJ, Collier PF. Low mortality rates in industrial cohort studies due to selection for work and survival in the industry. Brit J Prev Soc Med 1976;30:225-30.

17. Chiu WA, Caldwell JC, Keshava N, Scott CS. Key Scientific Issues in the Health Risk Assessment of Trichloroethylene. Environ Health Perspect 2006;114(9):1445-9. 
18. Scott CS, Chiu WA. Trichloroethylene Cancer Epidemiology: A Consideration of Select Issues. Environ Health Perspect 2006;114(9):1471-8.

19. Caldwell JC, Keshava N. Key Issues in the Modes of Action and Effects of Trichloroethylene Metabolites for Liver and Kidney Tumorigenesis. Environ Health Perspec 2006;114(9): 1457-63.

20. Hahn KM. Estimating Historic Exposure to Arsenic, Beryllium, Hexavalent Chromium, Nickel, and Uranium at a Uranium Enrichment, Gaseous Diffusion Plant [master thesis]. Findlay (OH): Univ. of Findlay; 2003.

21. Arrighi HM, Hertz-Picciotto I. The Evolving Concept of the Healthy Worker Survivor Effect. Epidemiology 1994;4(2): 189-96.

22. MandelJH, Kelsh MA, Mink PJ, Alexander DD, Kalmes RM, Weingart M, et al. Occupational trichloroethylene exposure and non-Hodgkin's lymphoma: a meta-analysis and review. Occup Environ Med 2006;63:597-607.

23. NIOSH. The staff of the health-related energy research branch division of surveillance, hazard evaluations, and fields studies National Institute for Occupational Safety and Health. Final Report. Mortality patterns among uranium enrichment workers at the Portsmouth Gaseous Diffusion Plant, Piketon, Ohio. Cincinatti: NIOSH; 2001.

24. Chan C, Hughes TS, Muldoon S, Aldrich T, Rice C, Hornung R, et al. Mortality patterns among Paducah Gaseous Diffusion Plant workers. J Occup Environ Med 2010;52(7): 725-32.

25. Oak Ridge Associated Universities Team (ORAUT). Technical Basis Document for the Paducah Gaseous Diffusion Plant — Site Description. ORAUT TKBS-0019-2. Oak Ridge (TN): ORAUT; 2006.

This work is available in Open Access model and licensed under a Creative Commons Attribution-NonCommercial 3.0 Poland License - http://creativecommons.org/ licenses/by-nc/3.0/pl/deed.en. 